\title{
The Ratio Effect of Tempeh Flour and Wheat Flour on the Characteristic of Sweet Bread
}

\author{
Aulia Azkia Hernawan*, Putri Afriliyanti and Ida Ningrumsari
}

\author{
Food Technology, Agriculture Faculty, Ma'soem University, Indonesia \\ *Corresponding author. Email: auliaazkia009@gmail.com
}

\begin{abstract}
A research to find out the ratio effect of tempeh flour and wheat flour on the characteristic of bread had been carried out. The research aimed to find out the right ratio between tempeh flour and wheat flour so that could produce sweet bread with acceptable characteristics. The experiment method was applied by using Randomized Block Design, and consisted of 4 treatments those were A: Ratio tempeh flour and wheat flour $(0$ : 100), B : Ratio tempeh flour and wheat flour (10:90), C : Ratio tempeh flour and wheat flour (15: 85), and D : Ratio tempeh flour and wheat flour $(20: 80)$. To find out the ratio effect of tempeh flour and wheat flour in bread making, some characteristics were observed such as swelling power and organoleptic test which were color, texture and flavor. Result of the study showed that the addition of tempeh flour effected on the characteristics of sweet bread. The ratio of 10: 90 produced the best characteristic of bread based on organoleptic test.
\end{abstract}

Keywords: Tempeh Flour, Wheat Flour, Ratio Effect, Sweet Bread, Characteristics

\section{INTRODUCTION}

Indonesia is one of the famous countries in traditional fermentation technology. One of the most popular fermentation food in Indonesia is tempeh. It is popular known base on its simple production technology, high nutrition content and economically cheap [1].

Tempeh production needs soybeans as raw material. In 1983 soybeans consumption Indonesia was 1.2 million tons, and the next 7 years (1990) was 1,8 million tons, from that total consumption about 1,048 million tons was consumed as tempeh. The data showed that tempeh consumption in Indonesia increased averagely $12 \%$ per year and about $57 \%$ of was consumed as tempeh, $38 \%$ as tofu and the rest as soy sauce, tauco, bean curd and others [2].

Tempeh is not only popular in Indonesia but it has been popular in Japan, USA and Europe. People need on tempeh from time to time has been increased significantly, since protein from meat and fish was expensive. The researchers have proved through their research's that tempeh contains protein equally to meat protein [3]. Every 100 grams of fresh tempeh contains 18.3 grams of protein whereas in every 100 grams meat contains 18.8 grams of protein, every 100 grams of egg contains 12.2 grams of protein [4].
At the beginning in Indonesia tempeh was known as side dishes. However, then its function has been changed along the time. Nowadays tempeh is not only as a final product, but it becomes material for the next diversification products. According to its advantage, tempeh can potentially be developed into other modern products.

Tempeh can be processed into flour. This form of flour gives added value such as it can be preserved for long time, and it can be processed into other foods. As flour, tempeh becomes a multifunction material [5].

Tempeh flour can possibly be used as raw material for making bread. The protein content in tempeh flour will be able to increase the nutrient content of bread. However, to produce bread from tempeh flour will cause an unexpected physical characteristic [6]. Base on that problem, a research is needed to find out the ratio effect of tempeh flour and wheat flour on the characteristic of bread, including the organoleptic characteristic such as flavor and appearance.

The research aim to find out the right ratio between tempeh flour and wheat flour so that can produce sweet bread with acceptable characteristics. 


\section{MATERIALS AND METHODS}

\subsection{Materials And Tools}

Tempeh flour, wheat flaour, sugar, salt, yeast,butter, egg , knife, baking sheet pan, chopping block, bamboo steamer, mixer, flour sifter, kichen scales, measuring cup, toaster oven and pan.

\subsection{The Research Method}

The experiment method was applied by using Randomized Block Design, and consisted of 4 treatments those were A : Ratio tempeh flour and wheat flour $(0: 100)$, B : Ratio tempeh flour and wheat flour (10:90), C : Ratio tempeh flour and wheat flour (15:85), and D : Ratio tempeh flour and wheat flour $(20: 80)$.

\subsection{The Production Procedure of Tempeh Flour}

1. Fresh tempeh was sliced with dimension $1 \times 4 \times 0.25 \mathrm{~cm}$

2. Blanching with hot steam of $100 \mathrm{oC}$ for 15 minutes

3. Sun drying for 24 hours

4. Dry material was blended then filtered with 80 mesh size

5. The final product (tempeh flour) was packed in plastic

\subsection{The Production Procedure of Bread}

1. Weighed tempeh flour and wheat flour according to every ratio, for example, for ratio $0: 100$ weighed 500 grams of wheat flour, for ratio $10: 90$ weighed 450 grams of wheat flour and 50 grams tempeh flour, for ratio $15: 85$ weighed 425 grams of wheat flour and 75 grams tempeh flour, for ratio $20: 80$ weighed 400 grams of wheat flour and 100 grams tempeh flour.

2. Yeast was dissolved into water and kept closed for 5 minutes to test whether the yeast active or not.

3. Wheat flour, tempeh flour and sugar were mixed and kneaded until dough became small granules, added eggs and mixed again.

4. Water and yeast were added slowly during kneading the dough.

5. Added margarine and salt

6. After the dough was not sticky anymore, it was formed like a ball then covered up using moist cloth for 30 minutes (fermentation I).

7. The cover was lift up, the swelled dough was smashed and kneaded, then divided into some balls each about 40 grams. Then covered it up once more with moist cloth for 10 minutes (fermentation II).

8. The dough would be much swelled then kneaded and formed like a ball placed onto a baking sheet, covered up for 40 minutes (fermentation III).

9. Baked using electric oven at $180 \mathrm{oC}$ for $12-15$ minutes

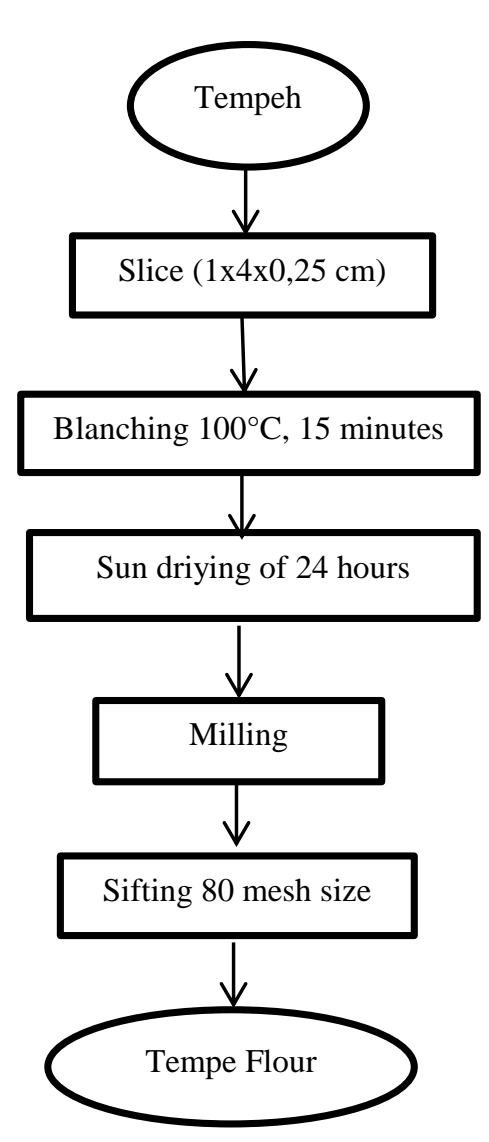

Figure 1. The Production Procedure of Bread

\subsection{The observation Criteria}

To find out the ratio effect of tempeh flour and wheat flour in bread making, some characteristics were observed such as swelling power and organoleptic test which were color, texture and flavor.

\subsection{The Analysis Procedure}

The method to measure bread swelling power:

1. The baking sheet was filled in by wheat flour until full. Then all the flour was taken away and measured using baker glass ( $\mathrm{V}=$ volume).

2. The dough (before fermentation period) was put on the baking sheet. Then wheat flour also put on that baking sheet until the rest of the space was full. The flour was taken away and measured using baker glass (Va).

3. After the fermentation period, the dough was put on the baking sheet. Wheat flour was put on the baking sheet until all the space was full. The flour was taken away and measured using baker glass $(\mathrm{Vb})$. 


\section{RESULTS AND DISCUSSION}

\subsection{The organoleptic test}

The organoleptic test was based on color, aroma, flavor and texture of sweet bread according to hedonic scaling. Rating was conducted by 15 panelist. The hedonic experiences of panelists were written on a particular form.

\subsection{Swelling power}

Ratio effect of tempeh flour and wheat flour showed a significant different on swelling power of sweet bread. The effect was shown in Table 1.

Table 1. The Ratio Effect of Tempeh Flour and Wheat Flour on Swelling Power of Sweet Bread

\begin{tabular}{cc}
\hline $\begin{array}{c}\text { Ratio Tempeh Flour : } \\
\text { Wheat Flour }\end{array}$ & $\begin{array}{c}\text { Swelling } \\
\text { Power }(\%)\end{array}$ \\
\hline $\mathrm{A}=0: 100$ & $68.73 \mathrm{~d}$ \\
$\mathrm{~B}=10: 95$ & $56.77 \mathrm{c}$ \\
$\mathrm{C}=15: 85$ & $49.32 \mathrm{~b}$ \\
$\mathrm{D}=20: 80$ & $42.69 \mathrm{a}$ \\
\hline
\end{tabular}

Table 1 indicated that the higher the proportion of tempeh flour the lower of the swelling power. The highest swelling power of sweet bread was reached by treatment A (no tempeh flour) $68.73 \%$, on the contrary, the lowest swelling power was by treatment D $(20: 80) 42.69 \%$. The decrease of swelling power was caused by the fact that tempeh flour didn't produce gluten in the dough. When we added more tempeh flour, gluten content would decrease so that the strength and elasticity decreased too.

The dough swelling was caused by $\mathrm{CO} 2$ which was caught by a unique system in the dough. This system related to the gluten character in wheat flour that managed to form a very thin elastic membrane since the presence of water and air in the dough. This membrane was able to envelop $\mathrm{CO} 2$ during the fermentation period [7].

\subsection{Color}

The ratio effect of tempeh flour and wheat flour showed a significant different based on color preference. The ratio effect of tempeh flour and wheat flour on color of sweet bread showed in Table 2.
Table 2. Ratio effect of Tempeh Flour and Wheat Flour on Color of Sweet Bread

\begin{tabular}{cc}
\hline Ratio Tempeh Flour : Wheat Flour & Color \\
\hline $\mathrm{A}=0: 100$ & $3.87 \mathrm{c}$ \\
$\mathrm{B}=10: 95$ & $3.72 \mathrm{~b}$ \\
$\mathrm{C}=15: 85$ & $3.72 \mathrm{~b}$ \\
$\mathrm{D}=20: 80$ & $3.18 \mathrm{a}$ \\
\hline
\end{tabular}

Table 2 showed that the higher the tempeh flour addition the lower the average of panelist preference on color. The treatment A (ratio $0: 100$ ) showed a significant different to other ratio. The color of sweet bread without tempeh flour addition was creamy. Tempeh flour addition on dough caused slightly dark color of bread. It might be effected by the original color of tempeh which was mastic, so that the bread color was slightly dark. The more the tempeh addition the darker the color of the bread.

\subsection{Flavor}

Ratio effect of tempeh flour and wheat flour showed a significant different on flavor as shown in tabel 3.

Table 3. Ratio Effect of Tempeh Flour and Wheat Flour on Flavor of Sweet Bread

\begin{tabular}{cc}
\hline Ratio Tempeh Flour : Wheat Flour & Flavor \\
\hline $\mathrm{A}=0: 100$ & $3.70 \mathrm{~b}$ \\
$\mathrm{~B}=10: 95$ & $3.68 \mathrm{~b}$ \\
$\mathrm{C}=15: 85$ & $2.92 \mathrm{a}$ \\
$\mathrm{D}=20: 80$ & $2.94 \mathrm{a}$ \\
\hline
\end{tabular}

Tabel 3 showed that the higher the tempeh flour addition the lower the average of panelist preference on flavor. The ratio $15: 85$ and $20: 80$ showed no significant different, however those showed a different effect with ratio $0: 100$ and $10: 90$. The more the addition of tempeh flour the preference on flavor shifted from indifferent toward dislike. Baking process caused browning reaction when sugar was caramelized, and sugar interacted with protein. Baking process caused starch decomposition and dextrin's formation those produced flavor component [8]. The panelist could still accept the ratio of $10: 90$.

\subsection{Texture}

Ratio effect of tempeh flour and wheat flour showed a significant different on texture as shown in Table 4. 
Table 4. Ratio Effect of Tempeh Flour and Wheat Flour on Texture of Sweet Bread

\begin{tabular}{cc}
\hline Ratio Tempeh Flour : Wheat Flour & Texture \\
\hline $\mathrm{A}=0: 100$ & $3.72 \mathrm{~b}$ \\
$\mathrm{~B}=10: 95$ & $3.67 \mathrm{~b}$ \\
$\mathrm{C}=15: 85$ & $3.34 \mathrm{a}$ \\
$\mathrm{D}=20: 80$ & $2.60 \mathrm{a}$ \\
\hline
\end{tabular}

Table 4 showed that the higher the tempeh flour addition the lower the average of panelist preference on texture. Treatment B (ratio of $10: 90$ ) produced sweet bread with good texture and acceptable by panelists. Meanwhile panelists disliked texture which was produced by tempeh flour more than $10 \%$. The usage of tempeh flour more than $15 \%$ produced bread with higher cohesiveness and the pores were uneven. Tempeh flour didn't produce gluten in dough so that more usage of tempeh flour would decrease the effect of gluten in dough and eventually the dough would be inelastic [9]. Moreover, texture of crumb was also effected by $\mathrm{CO} 2$ production during the fermentation period that would affect the porosity of bread crumb.

\section{CONCLUSION}

Result of the research showed that the addition of tempeh flour effected on characteristics of sweet bread. The ratio of 10 : 90 produced the best characteristic of bread based on organoleptic test.

It was recommended to increase the nutrition content of sweet bread by adding tempeh flour as much as $10 \%$.

\section{REFERENCES}

[1] D. N. Afifah, N. Nabilah, G. T. Supraba, S. N. Pratiwi, M. Sulchan. The effects of tempeh gembus, an Indonesian fermented food, on lipid profiles in women with hyperlipidemia. Current Nutrition \& Food Science, 16 (1) (2020) 56-64. DOI: https://doi.org/10.2 $174 / 1573401314666180807112549$

[2] A. Sarwono. Making Tempe and Oncom. Swada spreader. Jakarta, 1996

[3] A. M. S. Arini, D. N. Afifah, F. F. Dieny. The Effect of Tempeh Gembus Substitution on Protein Content, Calcium, Protein Digestibility and Organoleptic Quality of Meatballs. Current Research in Nutrition and Food Science Journal, 7(3), 828-841. DOI : http://dx.doi.org/10.12944/CRNFSJ.7.3.22
[4] A. Nussinovitch, M. Hirashima. More Cooking Innovations: Novel Hydrocolloids for Special Dishes. CRC Press.2018.

[5] S. Kurniawati, D. D. Lestiani, E. Damastuti, M. Santoso. The selenium content of Tempeh in Indonesia and its potential contribution to the dietary selenium requirements for adults. Journal of Food Composition and Analysis, 82 (2019) 103222. DOI : https://doi.org/1 0.1016/j.jfca.2019.05.005

[6] G. Jacobs, S. Tseng, P. Menezes. Tempted by Tempeh: 30 Creative Recipes for Fermented Soybean Cakes. Marshall Cavendish International Asia Pte Ltd.2019.

[7] G. d'Ippolito, S. Landi, N. Esercizio, M. Lanzilli, M. Vastano, L. Dipasquale, A. Fontana. CO2-induced transcriptional reorganization: molecular basis of Capnophillic lactic fermentation in Thermotoga neapolitana. Frontiers in microbiology, 11 (2020) 171. DOI : https://doi.org/10.3389/fmicb.2020.00171

[8] D. Goshima, K. Matsushita, J. Iwata, T. Nakamura, K. Takata, H. Yamauchi. Improvement of bread dough supplemented with crust gel and the addition of optimal amounts of bakery enzymes. Food Science and Technology Research, 25 (5) (2019) 625-636. DOI : https://doi.org/10.3136/fstr.25.625

[9] L. Huang, Z. Huang, Y. Zhang, S. Zhou, W. Hu, M. Dong. Impact of tempeh flour on the rheology of wheat flour dough and bread staling. LWT, 111 (2019) 694702. DOI : https://doi.org/10.1016/j.lwt.2019.04.004 